\title{
Genetic and morphologic differentiation of Bolbophorus confusus and B. levantinus (Digenea: Diplostomatidae), based on rDNA SSU polymorphism and SEM
}

\author{
R. Dzikowski ${ }^{1,3, *}$, M. G. Levy ${ }^{2}$, M. F. Poore ${ }^{2}$, J. R. Flowers' ${ }^{2}$, I. Paperna1 \\ ${ }^{1}$ Department of Animal Sciences, Faculty of Agriculture, Food and Environmental Sciences, the Hebrew University of Jerusalem, \\ PO Box 12, Rehovot 76100, Israel \\ ${ }^{2}$ Department of Population Health and Pathobiology, College of Veterinary Medicine, North Carolina State University, \\ 4700 Hillsborough St., Raleigh 27606, North Carolina, USA \\ ${ }^{3}$ Present address: Department of Microbiology and Immunology, Weill Medical College of Cornwell University, \\ 1300 York Avenue, W-704, Box 62, New York, New York 10021, USA
}

\begin{abstract}
Metacercariae of Bolbophorus species are serious pathogens of farmed fish. Molecular diagnostic tools, capable of identifying and differentiating these parasites, may assist in the development of rationale control strategies. The rDNA $18 \mathrm{~S}$ (small sub-unit: SSU) genes of adult $B$. confusus and B. levantinus obtained from a pelican, Pelecanus onocrotalus, and a night heron, Nycticorax nycticorax, respectively, were amplified, sequenced, and aligned. Based on this alignment, we developed a genetic differentiation assay between $B$. confusus and $B$. levantinus. These 2 species were compared genetically with the North American species B. damnificus and Bolbophorus sp. ('Type 2'). The relationship between species is outlined and discussed. In addition to the molecular study, specimens of $B$. confusus and $B$. levantinus were compared morphologically, using scanning electron microscopy. Morphologic analysis revealed interspecific differences in details of the holdfast organ and the position of the acetabulum.
\end{abstract}

KEY WORDS: Digenea - Diplostomatidae - Bolbophorus confusus - Bolobphorus levantinus · 18S (SSU) rDNA gene $\cdot$ SEM

Resale or republication not permitted without written consent of the publisher

\section{INTRODUCTION}

Metacercariae of Bolbophorus species induce massive infections in the muscles of fish, and consequent malformations and mortalities in fish from natural habitats and cultured fish ponds in both Israel and southern USA (Paperna 1996, Pasnik 1999, Veneble et al. 2000, Levy et al. 2002, Overstreet et al. 2002). The definitive host of B. confusus (Diplostomatidae) is the Eurasian white pelican Pelecanus onocrotalus (see Dubois 1938). In Europe, fish from diverse families (including Cyprinidae) are intermediate hosts for $B$. confusus (Bykhovskaya-Pavlovskaya et al. 1964, Dubois 1970), but the snail host remains unknown.
Paperna \& Lengy (1963) described the life cycle of Bolbophorus confusus levantinus from Israel, later designated by Dubois (1970) as a new species: B. levantinus. Its definitive hosts are herons, and metacercariae develop in cichlid fishes (Paperna 1996). A purple heron, Ardea purpurea, was experimentally infected by feeding it on naturally infected Tilapia zillii with metacercariae. Obtained trematode eggs successfully developed to cercaria stage in the snail Bulinus truncatus.

Overstreet et al. (2002) recently described a new species, Bolbophorus damnificus, from the North American white pelican P. erythrorhynchos. B. damnificus had previously been erroneously identified as $B$. 
confusus, but it differs from B. confusus by having larger eggs, and the vitellarium not reaching anterior to the holdfast organ. Furthermore, there is morphological and molecular evidence for the existence in North America of another species of Bolbophorus ('Type 2'), presently known only from immature specimens found in pelicans (Levy et al. 2002, Overstreet et al. 2002). Both recently discovered species were found to develop in the ram's horn snail Planorbella trivolis. Since the discovery of B. damnificus, the common pathogenic prodiplostomulum found in the flesh of the channel catfish Ictalurus punctatus has been identified as this species (Overstreet et al. 2002, Levy et al. 2002); the natural piscine host of Bolbophorus sp. 'Type 2' remains unknown.

Species-specific DNA probes have been developed for the North American species Bolbophorus damnificus and Bolboporus sp. 'Type 2', and have provided an important diagnostic tool for all stages of these trematodes, which are pathogenic as metacercariae to fish (Levy et al. 2002); experimental infections with Bolbophorus sp. 'Type 2' were highly pathogenic to several fish species (Levy et al. 2002).

The purpose of the present study was to develop a genetic differentiation assay between Bolbophorus confusus and B. levantinus, as well as to genetically compare the Old World with the New World species of the Bolbophorus genus.

\section{MATERIALS AND METHODS}

Sources of parasites and morphological characterization. Nine Bolbophorus levantinus Dubois 1970, were collected from mortally injured night heron Nycticorax nycticorax found in a fish farm on the Mediterranean coast of Israel. Hundreds of B. confusus (Krause 1914) Dubois 1935, were collected from the guts of a fall migrant Eurasian white pelican, Pelecantus onocrotalus, that had died of exhaustion in north Israel. Both species were collected by sedimentation and washing of scrapings from the anterior portion of the intestine. Collected trematodes were washed several times in physiological saline and preserved in $70 \%$ ethanol. Additional specimens of each species were fixed in $70 \%$ alcohol overnight, under light pressure between 2 cover glasses, to prepare them as stained whole mounts. Whole mounts were then stained in aceto-carmine, followed by differentiation in acid alcohol. For scanning electron microscopy (SEM), trematodes fixed in $70 \%$ ethanol were dehydrated in ascending alcohols, critical-point dried in liquid carbon dioxide in a 'Polaron E-3000' criticalpoint drying apparatus, and sputter-coated with gold in a 'Polaron E-5100' sputter-coater. Specimens were examined and photographed using a Joel JSM 35C SEM.

Gene amplification. Individual worms of each species were washed overnight in buffer TE $(10 \mathrm{mM})$, followed by 2 more $1 \mathrm{~h}$ washes prior to DNA extractions. DNA extraction, PCR amplification of the $18 \mathrm{~S}$ and internal transcribed spacer (ITS) genes, purification of PCR products and sequence determination and analysis were done following the same procedures described previously (Levy et al. 2002).

Species-specific oligonucleotide primers. Alignments of the rDNA small sub-unit (SSU) genes revealed polymorphic regions to which species-specific oligonucleotide primers were designed. The Bolbophorus confusus-specific primer set was composed of the forward primer Bcon 650F 5' GATTTCGGTTAGTTCAGG $3^{\prime}$, and the reverse primer Bcon 1470R 5' GGTCTACGGCCCAATC 3'. The B. levantinusspecific primer set was composed of the forward primer Pap180F 5' GGAGCGGCTTCGGCTGT 3', and the reverse primer Pap 600R 5' ATCATCGCCCGGAACTGA 3'. These oligonucleotides were used as both singleplex and multiplex configurations. PCRs were carried out in $50 \mu \mathrm{l}$ volumes using $10 \times$ buffer, 2.5 U Taq polymerase (HotStarTaq; Qiagen) $10 \mathrm{mM}$ of each deoxynucleoside triphosphate, and $100 \mathrm{ng}$ of each primer. The cycling conditions were as follows: $94^{\circ} \mathrm{C}$ for $15 \mathrm{~min}$ once, then 35 cycles of $94^{\circ} \mathrm{C}$ for $1 \mathrm{~min}, 58^{\circ} \mathrm{C}$ for $45 \mathrm{~s}$, and $72^{\circ} \mathrm{C}$ for $1 \mathrm{~min}$ followed by a final $5 \mathrm{~min}$ extension at $72^{\circ} \mathrm{C}$.

PCR amplicons were electrophoresed in 1.5\% agarose gels, stained with ethidium bromide and visualized under ultraviolet light.

Phylogenesis analysis. The rDNA SSU $\sim 1800 \mathrm{bp}$ nucleotide sequences of Bolbophorus confusus and $B$. levantinus were aligned with other available strigeid trematode sequences, including $B$. damnificus Overstreet, Curran, Pote, King, Blend, Grater 2002, and Bolbophorus sp. 'Type 2', Clinostomum complanatum and C. marginatum were utilized as out groups. The origin of sequences was from both the authors' material and GenBank. This was conducted using the aligning tool supplied by the ARB phylogenetic program package (Strunk \& Ludwig 1998 ${ }^{1}$ ). Phylogenetic trees were generated with the neighbor-joining and maximum-likelihood methods with the ARB program package, using the Felsenstein correction method applying a $50 \%$ cutoff filter. The topologies of the resulting trees were compared. Branching order was supported by both methods.

\footnotetext{
${ }^{1}$ Strunk O, Ludwig W (1998) ARB: a software environment for sequence data. Department of Microbiology, Technische Universität Munchen, Munich, available at http://mikro. biologie.tu-muenchen.de
} 


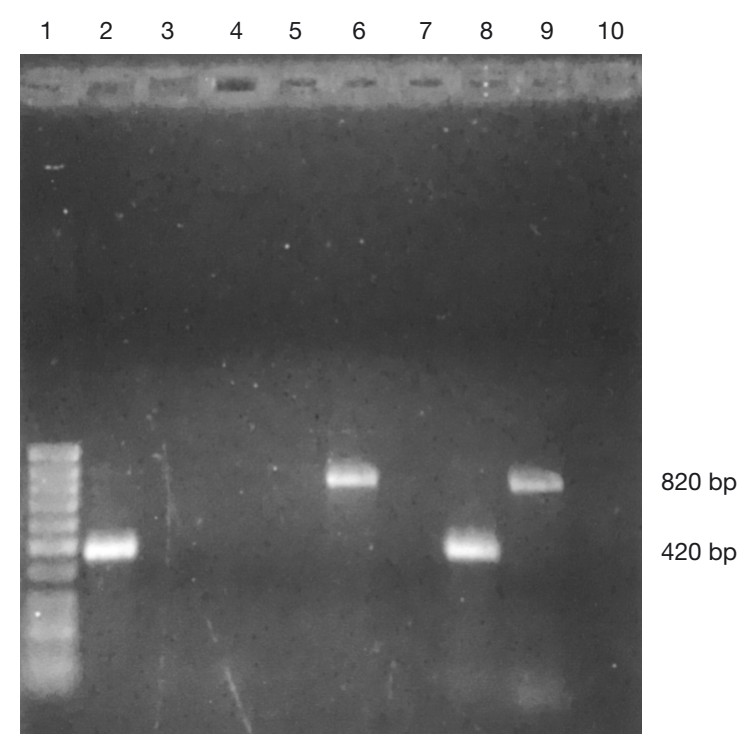

Fig. 1. Bolbophorus confusus and B. levantinus. PCR products of adult trematodes using species-specific PCR reactions with either single-species oligonucleotide primer sets (Lanes 2 to $4 \mathrm{~B}$. levantinus, Lanes 5 to $7 \mathrm{~B}$. confusus), or a multiplex configuration (Lanes 8 to 10). Lanes: $1=50 \mathrm{~kb}$ DNA marker; 2,5 and $8=B$. levantinus; 3,6 and $9=B$. confusus $; 4,7$ and $10=\mathrm{H}_{2} \mathrm{O}$

\section{RESULTS}

The rDNA SSU (18S) and ITS gene sequences were obtained from adult specimens of Bolbophorus confusus collected from the Eurasian white pelican, and compared to the sequence of $B$. levantinus from the night heron from Israel. Gene sequences were submitted to GenBank (accession numbers: B. levantinus = AF490576; B. confusus = AY242851).

PCR assay using singleplex and multiplex oligonucleotide primers designed for the polymorphic regions of the rDNA SSU of each species were developed and optimized. Under the conditions described above, $B$. confusus-specific singleplex yielded an $820 \mathrm{bp}$ amplicon, while $B$. levantinus-specific singleplex yielded a $420 \mathrm{bp}$ amplicon. PCR reactions containing the multiplex of all 4 oligonucleotide primers have been able to differentiate between the 2 species by producing the specific amplicon sizes for DNA of each species (Fig. 1). There was no cross-reaction of either the singleplexes or the multiplexes between the 2 species. There was also no cross-reaction of these sets with DNA from the pelican, the night heron, the freshwater snail Bulinus truncatus and the fish Tilapia zillii. Amplification of DNA from 2 North American Bolbophorus spp., B. damnificus and Bolbophorus sp. 'Type 2' (Levy et al. 2002, Overstreet et al. 2002), as well as DNA from other available trematode species infecting birds and fish in Israel, have failed to yield amplicons.
The species-specific singleplex/multiplex designed to differentiate between the 2 North American species (Levy et al. 2002) did not react with DNA of either Bolbophorus confusus or B. levantinus.

Phylogenetic analysis of 4 Bolbophorus spp., and their relationship to other trematode species of the order Strigeidida, based on SSU analysis, indicated that these species form a separate cluster for the genus Bolbophorus within the order. The genetic relatedness of these species, as demonstrated by this analysis, indicates significant relatedness between $B$. confusus and Bolbophorus sp. 'Type 2', and between B. levantinus and B. damnificus (Fig. 2).

Measurements and other morphological characteristics of Bolbophorus levantinus and B. confusus, obtained from whole mounts and SEM, were in agreement with previous reports (Paperna \& Lengy 1963, Dubois 1970). Of all B. confusus, only one contained any (4) eggs at all $(110-112 \times 50-53 \mu \mathrm{m}$ in size).

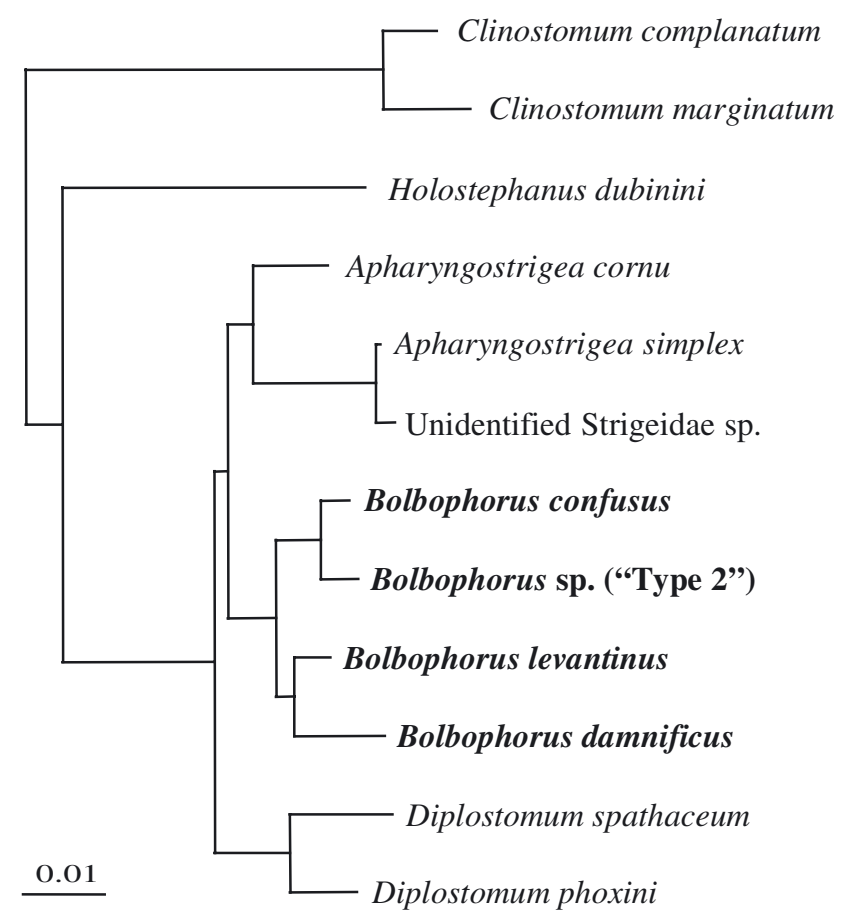

Fig. 2. Neighbor-joining phylogenetic analysis of 4 Bolbophorus species (bold) and their relation to other Strigeidae species, based on the rDNA small sub-unit (SSU) alignment. Scale bar $=1 \%$ estimate difference in nucleotide sequence positions. GenBank accession numbers: Clinostomum complanatum = AY245701; C. marginatum = AY25760; Holostephanus dubinini $=$ AY245707; Apharyngostrigea cornu $=$ AY245756; A. simplex = AY245757; unidentified Strigeidae sp. $=$ AY245711; B. confusus $=$ AY242851; Bolbophorus sp. ('Type 2') = AF490575; B. levantinus = AF490576; B. damnificus $=$ AF490574; Diplostomum spathaceum $=$ AY245761 D. phoxini $=$ AJ287503 


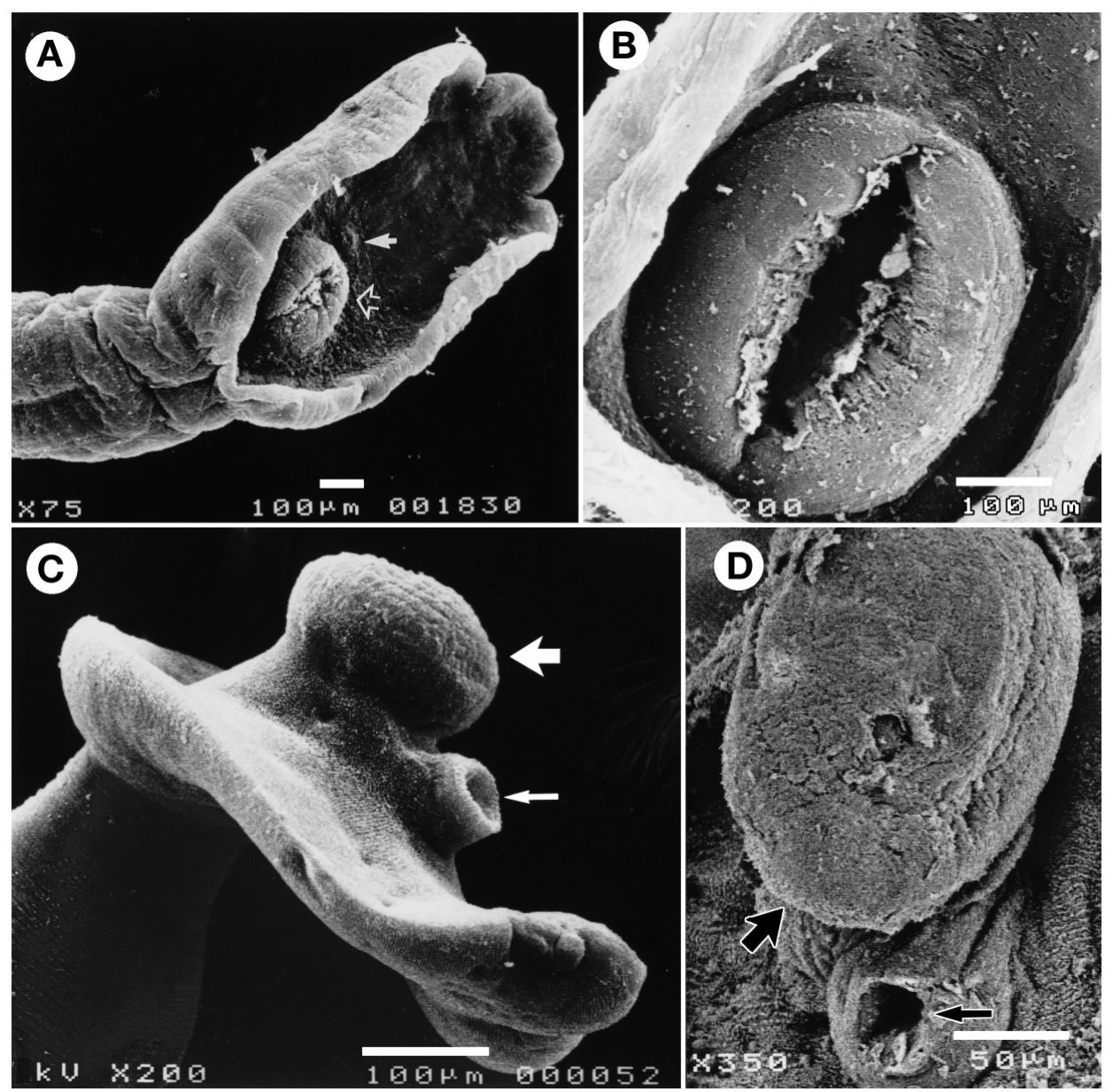

Fig. 3. Bolbophorus confusus and B. levantinus. Scanning electron micrograph of (A) B. confusus: lateral view of the whole worm: acetabulum (white arrow) and holdfast organ (hollow arrow); (B) B. confusus: lateral view of the holdfast organ; (C) B. levantinus: lateral view of the anterior part of the body: acetabulum (thin arrow) and holdfast organ (thick arrow); (D) B. levantinus: ventral view of the acetabulum (thin arrow) and holdfast organ (thick arrow)

Specimens of B. levantinus did not contain eggs. The distance between the posterior part of the holdfast organ and the anterior part of the acetabulum was 132 to $140 \mu \mathrm{m}$ in $B$. confusus and only 30 to $35 \mu \mathrm{m}$ in $B$. levantinus. The holdfast organ of $B$. confusus protruded slightly from the surface, with a medial longitudinal slit (Fig. 3A,B); however, the holdfast organ of B. levantinus protruded robustly from the surface, and the medial longitudinal slit was absent (Fig. 3C,D). The SEM image of $B$. levantinus' body surface shows it to be covered with spines, which are absent in B. confusus (Fig. 3).

\section{DISCUSSION}

The genetic divergence in the sequence of the rDNA SSU between Bolbophorus confusus and B. levantinus validates past classification by morphological criteria
(Dubois 1970). The SEM study of these species further highlights structural differences between the species, particularly in the details of the holdfast organ and the position of the acetabulum (lack of spine cover in $B$. confusus may be attributable to a postmortem artifact). Polymorphisms in the SSU allowed us to develop a sensitive, species-specific assay for these 2 trematodes. The applications of this assay are not only for taxonomical purposes, but also for the study of transmission aspects of these parasites, which are serious pathogens to fish (Paperna 1996). The methodology we developed allows us to identify infection in molluscan and piscine hosts. So far, the molluscan host of $B$. confusus is unknown. A similar molecular methodology has recently been applied to provide a link between the adult and juvenile stages of the North American species B. damnificus and Bolbophorus sp. 'Type 2' (Levy et al. 2002).

Overstreet et al. (2002) have shown that Bolbophorus sp. found in North American hosts (pelicans), and 
previously regarded as conspecific with $B$. confusus found in Old World pelicans, are in fact a distinct species (B. damnificus). Fox (1965) identified the planorbid snail Planorbella (syn. Helisoma) trivolis as $B$. damnificus' first intermediate host. Pasnik (1999) and Venable et al. (2000) reported metacercarial infection in channel catfish Ictalurus punctatus. In the present study, we provided genetic evidence that $B$. damnificus found in American pelicans is also a species distinct from B. confusus, which infects the Eurasian white pelican.

Genetic relatedness between the 4 studied species of Bolbophorus, based on molecular data obtained from the SSU rDNA gene sequences, indicated closest similarity between B. confusus and Bolbophorus sp. 'Type 2 ', and similarly between $B$. levantinus and $B$. damnificus. This implies that the species from a pelican ( $B$. damnificus) is closer to the species from a heron (B. levantinus) from the other side of the Atlantic than to that from the pelican (Bolbophorus sp. 'Type 2') from the same continent. The reasons for closer genetic similarity of the rDNA SSU between Bolbophorus spp. from 2 different continents, compared with species from the same continent, remains a challenging question for further investigations. Genetic comparison with further specimens documented from other parts of the world (Australia, Philippines, Vietnam, India, the Nile River Valley and central Africa; Dubois 1970) may alter our taxonomical concept of this group, and provide further clues to the understanding of the evolution of the Bolbophorus species.

Acknowledgements. This study was supported by the USIsrael Binatinal Science Foundation (BSF), Project No. 1999007.

Editorial responsibility: Wolfgang Körting, Hannover, Germany

\section{LITERATURE CITED}

Bykhovskaya-Pavlovskaya IE, Gusev AV, Dubinina MN, Izyumova NA and 5 others (1964) Key to the parasites of freshwater fish of the USSR. Israel Program for Scientific Translations, Jerusalem

Dubois G (1938) Monographie des Strigeida (Trematoda). Memoires de la Société Neuchateloise des Sciences Naturelles, Vol VI. Université de Neuchatel, Suisse

Dubois G (1970) Synopsis des Strigeidae et des Diplostomatidae (Trematoda). Mem Soc Neuchateloise Sci Nat 10:259-727

Fox AC (1965) The life cycle of Bolbophorus confusus (Krause, 1914) Dubois 1935 (Trematoda, Strigeoidea) and the effect of the metacerceriae on fish hosts. PhD Dissertation, Montana State University, Bozeman

Levy MG, Flowers JR, Poore MF, Khoo L and 5 others (2002) Morphologic, pathologic, and genetic investigations of Bolbophorus spp. (Diplostomatida, Trematoda) affecting cultured Ictalurus punctatus in the Mississippi Delta. J Aquat Anim Health 14:235-246

Overstreet RM, Curran SS, Pote LM, King DT, Blend CK, Grater WD (2002) Bolobophorus damnificus n. sp. (Digenea: Bolobophoridae) from the channel catfish Ictalurus punctatus and the American white pelican Pelecantus erythrorhynchos in the USA based on life cycle and molecular data. Syst Parasitol 52:81-96

Paperna I (1996) Parasites, infections and diseases of fishes in Africa-an update. Central Institute of Freshwater Aquaculture, Technical Paper 31, Food and Agriculture Organization, United Nations, Rome

Paperna I, Lengy J (1963) Notes on a new subspecies of Bolobophorus confusus (Krause, 1914) Dubois, 1935 (Trematoda: Diplostomatidae). A fish-transmitted bird parasite. Isr J Zool 12:171-182

Pasnik D (1999) Research of the new trematode in channel catfish. Fish Farming News Nov/Dec:40-42

Venable DL, Gaude AP III, Klerks PL (2000) Control of the trematode Bolbophorus confusus in channel catfish Ictalurus punctatus ponds using salinity manipulation and polyculture with black carp Mylopharyngodon piceus. J World Aquac Soc 31:158-166

Submitted: June 2, 2003; Accepted: August 16, 2003 Proofs received from author(s): December 16, 2003 